\title{
A SEMI-AUTOMATIC RULE SET BUILDING METHOD FOR URBAN LAND COVER CLASSIFICATION BASED ON MACHINE LEARNING AND HUMAN KNOWLEDGE
}

\author{
H. Y. Gu ${ }^{\text {a, } *, H . T . ~ L i ~}{ }^{\text {a }}$ Z.Y. Liu ${ }^{\text {a }}$, C. Y. Shao ${ }^{\text {a }}$
}

${ }^{\text {a }}$ Photogrammetry and Remote Sensing, Chinese Academy of Surveying and Mapping, 28 Lianhuachi Road, Beijing, P.R. China (guhy,lhtao,zjliu)@casm.ac.cn

\section{Commission VI, WG VI/4}

KEY WORDS: Land cover classification, Rule set, Machine learning, Human knowledge

\begin{abstract}
:
Classification rule set is important for Land Cover classification, which refers to features and decision rules. The selection of features and decision are based on an iterative trial-and-error approach that is often utilized in GEOBIA, however, it is time-consuming and has a poor versatility. This study has put forward a rule set building method for Land cover classification based on human knowledge and machine learning. The use of machine learning is to build rule sets effectively which will overcome the iterative trial-and-error approach. The use of human knowledge is to solve the shortcomings of existing machine learning method on insufficient usage of prior knowledge, and improve the versatility of rule sets. A two-step workflow has been introduced, firstly, an initial rule is built based on Random Forest and CART decision tree. Secondly, the initial rule is analyzed and validated based on human knowledge, where we use statistical confidence interval to determine its threshold. The test site is located in Potsdam City. We utilised the TOP, DSM and ground truth data. The results show that the method could determine rule set for Land Cover classification semiautomatically, and there are static features for different land cover classes.
\end{abstract}

\section{INTRODUCTION}

Classification rule set is an important method for remote sensing image classification (Forestier, 2012). Rau presented a semiautomatic landslide recognition method using rule set, and validated that the rule set was suitable for various landslide (Rau, 2014). Ziaei presented a rule-based parameter aided with object-based classification approach for extraction of building and roads from WorldView-2 images (Ziaei, 2014).Yu explored the potential role of feature selection in global land-cover mapping (Yu, 2016). Chen measured the effectiveness of various features for thematic information extraction from very high resolution remote sensing imagery (Chen, 2015). However, these methods usually use semiautomatic detection, empirical description and fuzzy function classification. The whole process not only needs supervision, but also requires manual production. Against this background, the next section discusses a semiautomatic rule set building method based on machine learning and human knowledge. The use of machine learning is to build rule sets effectively which will overcome the iterative trial-anderror approach. The use of human knowledge is to solve the shortcomings of existing machine learning method on insufficient usage of prior knowledge, and improve the versatility of rule sets. Urban Land-cover classification test is carried out in order to validate the performance of the method.

\section{METHOD}

\subsection{Rule Set based on Machine Learning}

2.1.1 Feature Selection based on Random Forest: The Random Forest (RF) machine learning method is an ensemble classifier developed by Leo Breiman in 2001, based on multiple decision trees. It is a relatively new, non-parametric, data-driven classification method that can create a classification model automatically by learning and training using samples provided by the RS expert, without requiring any prior input (Breiman, 2001). It has the ability to analyze complex features and is robust for noisy and missing data; it is also able to estimate the importance of features and has a faster learning speed and greater accuracy than other similar algorithms that are currently popular (Breiman, 2001).

The RF classifier offers an internal feature evaluation step, through which it is able to estimate the importance of a particular feature, and to subsequently guide the construction of classification rules using significant features only, whereas a general classification method does not offer any form of feature evaluation. It is also able to use a smaller number of features and thus reduce computing time and memory requirements, with no detrimental effect on performance.

The importance of the features is estimated by the RF algorithm, the difference between the current OOB (Out Of Bag) error and the previous OOB error is taken to represent the importance of the variable (Verikas, 2011). Variables with higher values are considered to be more important to the classification than those with lower values. Given a sample subset $(\mathrm{s}=1,2, \ldots, \mathrm{S})$ the 
computation of the importance value $\left(\mathrm{D}_{\mathrm{j}}\right)$ of feature $\mathrm{x}_{\mathrm{j}}$ is as follows:

(a) When $s=1$, the OOB data $L_{s}^{o o b}$ are classified by decision tree $T_{s}$, and the classification number is recorded as $N_{s}^{o o b}$.

(b) For variable $x_{j}, j=1,2, \ldots, \mathrm{N}$. When $x_{j}$ is changed, then $L_{s}^{o o b}$ is also changed and recorded as $L_{s j}^{o o b} ; L_{s j}^{o o b}$ is classified by decision tree $T_{s}$ and the classification number is recorded as $N_{s j}^{o o b}$.

(c) For $s=2, \ldots$, S, repeat steps (a) and (b).

(d) The formula for the importance value $\left(D_{j}\right)$ of feature $x_{j}$ is then: $D_{j}=1 / S \sum\left(N_{s}^{o o b}-N_{s j}^{o o b}\right)$.

2.1.2 Rule Set Building based on CART: CART is forecasted and classified by constructing binary tree. It has the characteristics of simple model construction, accurate prediction and reusable decision tree rules. This study uses CART for object-based image classification, on the one hand, to test the representative of the features, on the other hand, to reuse the decision tree for other similar image. It includes training and testing steps: (a) Training step. The Gini coefficient of each attribute of the training sample is calculated according to the principle of Gini coefficient gain as the classification condition. After a node generates left and right nodes, the decision tree is generated recursively to divide the left and right nodes, and the decision tree is simplified by pruning method, then the decision tree model is got. (b) Testing step. All the objects are classified by CART decision tree model, and the classification results are obtained.

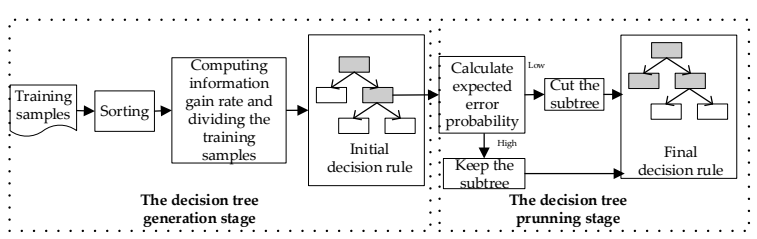

Figure 1. Decision rule based on CART.

\subsection{Rule Set based on Human Knowledge}

The description and decision rules of eight land-covers are shown in Table 1.

Table 1. The description and rule set of eight land-covers.

\begin{tabular}{|c|c|c|}
\hline & Description & Rule Set \\
\hline Field & $\begin{array}{l}\text { Field is often cultivated } \\
\text { for planting crops, which } \\
\text { includes cooked field, } \\
\text { new developed field and } \\
\text { grass crop rotation land. It } \\
\text { is mainly for planting } \\
\text { crops, and there are } \\
\text { scattered fruit trees, } \\
\text { mulberry trees or others. }\end{array}$ & $\begin{array}{l}\text { Regular } \cap \\
\text { Planar } \cap \\
\text { Smooth } \cap \text { Dark } \\
\cap \text { Low } \cap \\
\text { adjacentToRoa } \\
\text { d. }\end{array}$ \\
\hline Orchard & $\begin{array}{l}\text { Orchard is artificially } \\
\text { cultivated for perennial } \\
\text { woody and herbaceous } \\
\text { crops. It is mainly used } \\
\text { for collecting fruits, } \\
\text { leaves, roots, stems, etc. It } \\
\text { also includes various }\end{array}$ & $\begin{array}{l}\text { Regular } \cap \\
\text { Planar } \cap \\
\text { Smooth } \cap \text { Dark } \\
\cap \text { Medium } \cap \\
\text { adjacentToFiel } \\
\text { d. }\end{array}$ \\
\hline
\end{tabular}

\begin{tabular}{|c|c|c|}
\hline & $\begin{array}{l}\text { trees, bushes, tropical } \\
\text { crops and fruit nursery, } \\
\text { etc. }\end{array}$ & \\
\hline Woodland & $\begin{array}{l}\text { Woodland is covered of } \\
\text { natural forest, secondary } \\
\text { forest and plantation, } \\
\text { which includes trees, } \\
\text { bushes, bamboo, etc. }\end{array}$ & $\begin{array}{l}\text { Irregular } \cap \\
\text { Planar } \cap \\
\text { Rough } \cap \text { Dark } \\
\cap \text { High } \cap \\
\text { adjacentToFiel } \\
\text { d. }\end{array}$ \\
\hline Grassland & $\begin{array}{l}\text { Grassland is covered of } \\
\text { herbaceous plants, which } \\
\text { includes shrub grassland, } \\
\text { pastures, sparse grassland, } \\
\text { etc. }\end{array}$ & $\begin{array}{l}\text { Irregular } \cap \\
\text { Planar } \cap \\
\text { Smooth } \cap \text { Dark } \\
\cap \\
\text { Low } \text { adjacent } \\
\text { ToBuilding. }\end{array}$ \\
\hline Building & $\begin{array}{l}\text { Building includes } \\
\text { contiguous building areas } \\
\text { and individual buildings } \\
\text { in urban and rural areas. }\end{array}$ & $\begin{array}{l}\text { Regular } \cap \\
\text { Planar } \cap \\
\text { Rough } \cap \text { Light } \\
\cap \text { High } \cap \\
\text { adjacentToRoa } \\
\text { d. }\end{array}$ \\
\hline Road & $\begin{array}{l}\text { Road is covered by rail } \\
\text { and trackless road surface, } \\
\text { including railways, } \\
\text { highways, urban roads } \\
\text { and rural roads. }\end{array}$ & $\begin{array}{l}\text { Regular } \cap \text { Strip } \\
\cap \text { Smooth } \cap \\
\text { Light } \cap \text { Low } \cap \\
\text { adjacentToBuil } \\
\text { ding. }\end{array}$ \\
\hline Bare land & $\begin{array}{l}\text { Bare land is a variety of } \\
\text { natural exposed surface } \\
\text { (forest coverage is less } \\
\text { than } 10 \% \text { ). }\end{array}$ & $\begin{array}{l}\text { Irregular } \cap \\
\text { Planar } \cap \\
\text { Rough } \cap \text { Light } \\
\cap \text { Low. }\end{array}$ \\
\hline Water & $\begin{array}{l}\text { Water includes all types } \\
\text { of surface water. }\end{array}$ & $\begin{array}{l}\text { Irregular } \cap \\
\text { Planar } \cap \\
\text { Smooth } \cap \text { Dark } \\
\cap \text { Low. }\end{array}$ \\
\hline
\end{tabular}

For example, mark rules are shown as follows:

- RectFit (?x, ?y), greaterThanOrEqual(?y, 0.5) -> Regular (?x);

- RectFit (?x, ?y), lessThan(?y, 0.5) -> Irregular (?x);

- LengthWidthRatio(?x, ?y), greaterThanOrEqual(?y, 1) -> Strip(?x);

- LengthWidthRatio(?x, ?y), lessThan (?y, 1) -> Planar(?x);

This means RectFit of an object $>0.5$ denotes Regular shape, where $<0.5$ denotes Irregular shape. The thresholds are obtained by a statistical confidence interval approach.

\subsection{Statistical Confidence Interval}

In statistics, a confidence interval is a type of interval estimate of population parameter constructed by the sample statistic. Two-side confidence limits from a confidence interval and oneside limits are referred to as lower/upper confidence bounds (or limits). The affect factors include the size of samples and the confidence level. In the case of a fixed confidence level, the more the samples, the narrower the confidence interval. In the case of a fixed samples, the higher the confidence level, the wider the confidence interval. The confidence interval is defined as:

\section{$[\mathrm{M}-\mathrm{N} * \mathrm{STD}, \mathrm{M}+\mathrm{N} * \mathrm{STD}]$}

Where, $\mathrm{M}$ is the mean of the sample, STD is the standard deviation of the sample, $\mathrm{N}$ is used as the critical value. 


\section{EXPERIMENT AND ANALYSIS}

\subsection{Data}

The data set is in the city of Potsdam. We used true orthophoto (TOP) data with four channels red, green, blue, infrared, and the DSM and ground truth (ISPRS, 2017). The TOP and DSM are used for classification, the ground truth is used for sample selection.

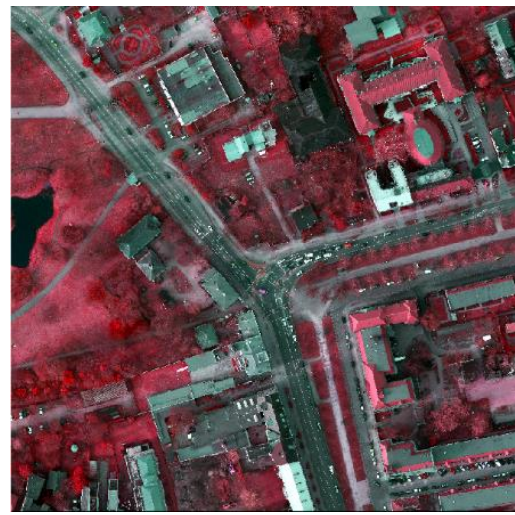

(a) True orthophoto (TOP) data

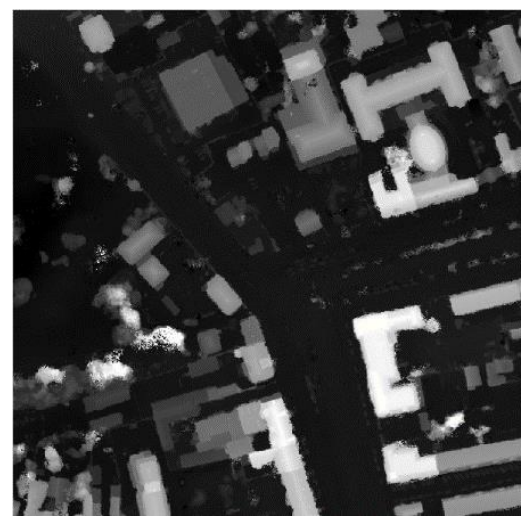

(b) DSM

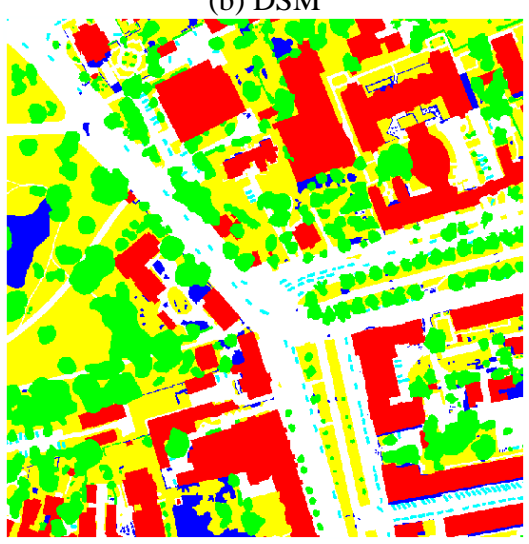

(c) Ground truth data

Figure 2. Data set in Potsdam

\subsection{Experiment}

(1) Segmentation. Firstly, we use ArcGIS to make the ground truth data as a vector constraints. Then we use eCognition for multi-resolution segmentation. The trial-and-error method is adopted to find an approximate and reasonable scale parameter, where the scale is set to 100 , the shape factor weight is 0.2 and compactness factor weight is 0.8 .
(2) Feature Selection. Sixteen features (e.g., ratio, mean, Normalized Difference Water Index, Normalized Difference Vegetation Index, homogeneity, and brightness) are selected, and then are sorted using RF. The feature importance of Potsdam is shown in figure 3 .

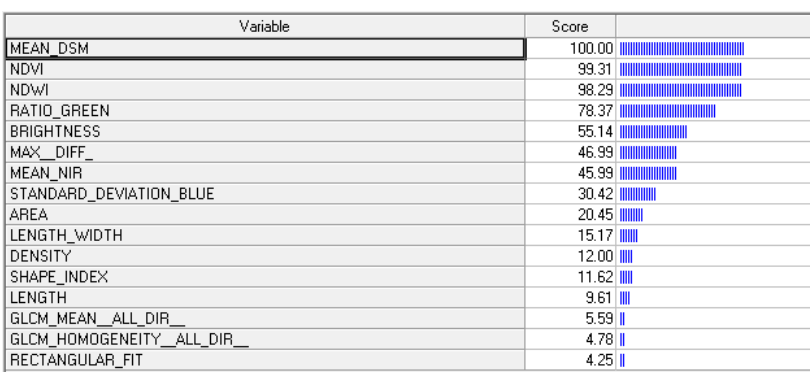

Figure 3. The feature importance of Potsdam

(3) Decision Rules Building. The initial decision rules are built using CART. Which is shown in figure 4 and table 2.

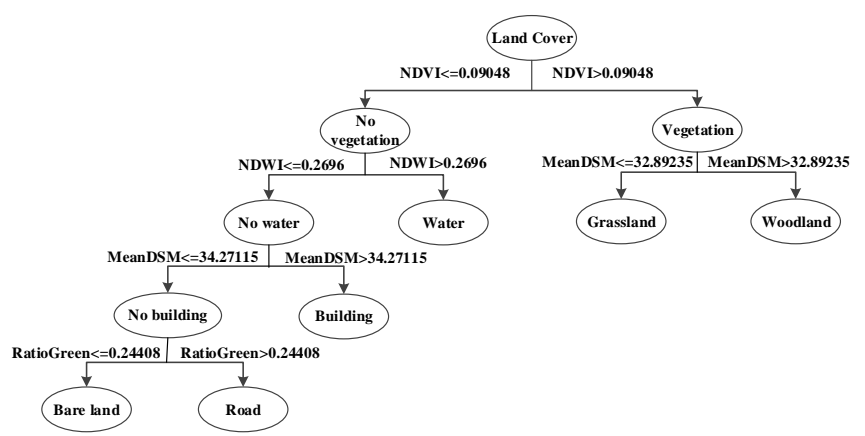

Figure 4. The decision rules of Potsdam

Table 2. Decision rules

\begin{tabular}{cll}
\hline Class & \multicolumn{1}{c}{ Decision rules } \\
\hline Woodland & NDVI $>0.09048 \&$ MeanDSM $>32.89235$ \\
Grassland & NDVI $>0.09048 \&$ MeanDSM $<=32.89235$ \\
Building & NDVI $<=0.09048 \quad \&$ NDWI $\quad<=0.269 \&$ \\
& MeanDSM $>34.27115 \quad$ NDI $\quad<=0.269 \&$ \\
Road & NDVI $<=0.09048 \quad \&$ NDWI \\
& MeanDSM $<=34.27115 \&$ & \\
& RatioGreen $>0.24408 \quad$ NDI $>0.269 \quad$ \\
Water & NDVI $<=0.09048 \&$ NDW $\quad<=0.269 \&$ \\
Bare land & NDVI $<=0.09048 \quad \&$ NDWI \\
& MeanDSM $<=34.27115 \&$ & \\
& RatioGreen $<=0.24408$ & \\
\hline &
\end{tabular}

(4) Decision Rules validation. The initial rule is validated based on human knowledge and membership function, where we use statistical confidence interval to determine its threshold. For example, the confidence interval of building is shown in table 2 .

Table 3. The confidence interval of building

\begin{tabular}{cccc}
\hline $\begin{array}{c}\text { Object } \\
\text { types }\end{array}$ & Features & $\begin{array}{c}\text { Member } \\
\text { ship } \\
\text { function }\end{array}$ & Confidence interval \\
\hline building & $\begin{array}{c}\text { DSM } \\
\text { ratioG }\end{array}$ & $>$ & $\begin{array}{c}{\left[\mathrm{DSM}_{\mathrm{M}-\mathrm{N} * \text { std }}, \mathrm{DSM}_{\mathrm{M}}\right]} \\
{[\text { ratioG }}\end{array}$, ratioG $\left.\mathrm{M}+\mathrm{N} * \mathrm{std}\right]$ \\
\hline
\end{tabular}

(5) Classification. The image are classified using CART, and then are validated using human knowledge and membership function. The 


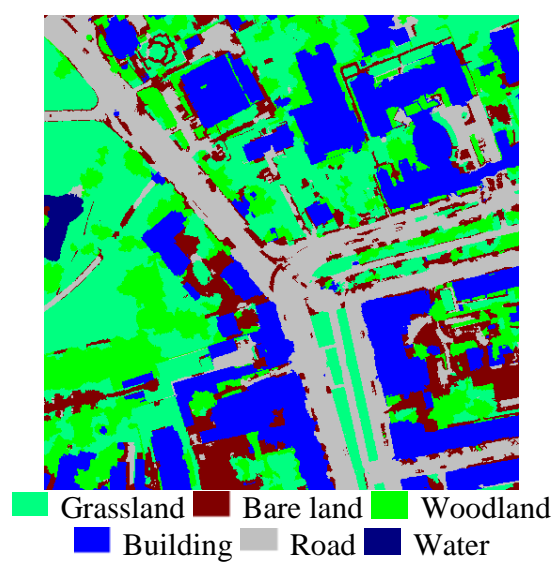

Figure 5. Classification results of Potsdam

\subsection{Analysis}

An accuracy assessment was carried out. A sample-based error matrix is created and used for performing accuracy assessment. In GEOBIA, a sample refers to an object. The error matrix for the test area is shown in Figure 16. The user's accuracy, producer's accuracy, overall accuracy and Kappa coefficient is shown in Table 4.

Table 4. Overall accuracy.

\begin{tabular}{|c|c|c|c|c|c|c|c|c|}
\hline & $\begin{array}{l}\text { gra } \\
\text { ssl } \\
\text { an } \\
\text { d }\end{array}$ & road & $\begin{array}{l}\text { woo } \\
\text { dlan } \\
\text { d }\end{array}$ & $\begin{array}{l}\text { bu } \\
\text { ild } \\
\text { ing }\end{array}$ & $\begin{array}{l}\text { wate } \\
\mathrm{r}\end{array}$ & $\begin{array}{l}\text { bar } \\
\text { ela } \\
\text { nd }\end{array}$ & $\begin{array}{l}\text { ov } \\
\text { era } \\
\text { ll }\end{array}$ & UA \\
\hline $\begin{array}{l}\text { grasslan } \\
\text { d }\end{array}$ & 30 & 0 & 1 & 0 & 0 & 0 & 31 & 96.77 \\
\hline road & 0 & 28 & 0 & 0 & 1 & 0 & 29 & 96.55 \\
\hline $\begin{array}{l}\text { woodla } \\
\text { nd }\end{array}$ & 0 & 0 & 29 & 0 & 0 & 0 & 29 & 100 \\
\hline building & 0 & 0 & 0 & 30 & 0 & 0 & 30 & 100 \\
\hline water & 0 & 0 & 0 & 0 & 5 & 0 & 5 & 100 \\
\hline $\begin{array}{l}\text { barelan } \\
\text { d }\end{array}$ & 0 & 2 & 0 & 0 & 0 & 8 & 10 & 80 \\
\hline overall & 30 & 30 & 30 & 30 & 6 & 8 & $\begin{array}{l}13 \\
4\end{array}$ & \\
\hline РA\% & $\begin{array}{l}10 \\
0\end{array}$ & $\begin{array}{l}93.3 \\
3\end{array}$ & $\begin{array}{l}96.6 \\
7\end{array}$ & $\begin{array}{l}10 \\
0\end{array}$ & $\begin{array}{l}83.3 \\
3\end{array}$ & $\begin{array}{l}10 \\
0\end{array}$ & & \\
\hline \multicolumn{9}{|c|}{$\mathrm{OA}=97.01 \%, \mathrm{Kappa}=0.96$} \\
\hline
\end{tabular}

The overall accuracy is $97.01 \%$, and the kappa coefficient is 0.96. Our method yields improvements as it depends on decision rule based on machine learning and human knowledge. This is based on the initial decision rules and the validation process, and some obvious classification errors may be corrected already within the following validation step.

\section{CONCLUSION}

This study has put forward a rule set building method for Land cover classification based on human knowledge and machine learning. The use of machine learning is to build rule sets effectively which will overcome the iterative trial-and-error approach. The use of human knowledge is to solve the shortcomings of existing machine learning method on insufficient usage of prior knowledge, and improve the versatility of rule sets. A two-step workflow has been introduced, firstly, an initial rule is built based on Random Forest and CART decision tree. Secondly, the initial rule is analyzed and validated based on human knowledge, where we use statistical confidence interval to determine its threshold. The test site is located in Potsdam City. We utilised the TOP,
DSM and ground truth data. The results show that the method could determine rule set for Land Cover classification semiautomatically, and there are static features for different land cover classes.

Nevertheless, the method is still in the process of development and improvement. Further in-depth studies may be required to (a) improve and refine rule set using human knowledge, (b) investigate the factors influencing classification, such as the spatial scale, the segmentation method employed, and the choice of samples, and (c) to investigate the automation of the method.

\section{ACKNOWLEDGEMENTS}

This research was funded by: (1) the National Natural Science Foundation of China (Project Nos. 41371406, 41471299, and 41671440); (2) Central Public-interest Scientific Institution Basal Research Fund (Project Nos. 7771508, 777161101, and 777161102).

\section{REFERENCES}

Breiman, L, Cutler, A. Random Forests; Available online: http://www.stat.berkeley.edu/users/breiman/RandomForests/cc_ home.htm (accessed on 5 March 2017).

Breiman, L., 2001. Random Forests. Mach. Learn. 45, 5-32.

Chen X, Fang T, Huo H, Li D R., 2015. Measuring the Effectiveness of Various Features for Thematic Information Extraction From Very High Resolution Remote Sensing Imagery. IEEE Transactions On Geoscience And Remote Sensing, 53(9):4837-4851.

Forestier G, Puissant A, Wemmert C, et al., 2012. Knowledgebased region labeling for remote sensing image interpretation. Computers, Environment and Urban Systems, 36(5): 470-480.

ISPRS Test Project on Urban Classification, 3D Building Reconstruction and Semantic Labeling. http://www2.isprs.org/commissions/comm3/wg4/2d-sem-labelpotsdam.html. (accessed on 5 March 2017).

Rau J Y, Jhan J P, Rau R J., 2014. Semiautomatic ObjectOriented Landslide Recognition Scheme From Multisensor Optical Imagery and DEM. Geoscience \& Remote Sensing IEEE Transactions on, 52(2):1336-1349.

Verikas, A., Gelzinis, A., Bacauskiene, M. Mining data with random forests: A survey and results of new tests. Pattern Recognit. 2011, 44, 330-349.

Yu L, Fu H H, Wu B, Clinton N, Gong P., 2016. Exploring the potential role of feature selection in global land-cover mapping. International journal of remote sensing, 37(23): 5491-5504.

Ziaei Z, Pradhan B, Mansor S B., 2014. A rule-based parameter aided with object-based classification approach for extraction of building and roads from WorldView-2 images. Geocarto International, 29(5):554-569. 